\title{
The Distribution of Free Calcium in Transected Spinal Axons and Its Modulation by Applied Electrical Fields
}

\author{
Alan F. Strautman, ${ }^{\text {a }}$. John Cork, and Kenneth R. Robinson \\ Department of Biological Sciences, Purdue University, West Lafayette, Indiana 47907
}

Intracellular free-calcium concentration $\left(\left[\mathrm{Ca}^{2+}\right]_{i}\right)$ was measured in lamprey spinal axons using the fluorescent calcium indicator fura 2 . We used both a photomultiplier tube and a video-image processing system to measure the temporal and spatial distributions of $\left[\mathrm{Ca}^{2+}\right]_{i}$ in the proximal segments of transected axons. Within $3 \mathrm{~min}$ following transection, a spatially graded increase in the $\left[\mathrm{Ca}^{2+}\right]_{i}$ was apparent in the last few millimeters of the axons. Superimposed on the initial gradient was a moving front of calcium that progressed up the axon, reaching $1.6 \mathrm{~mm}$ from the cut end in $3 \mathrm{hr}$. The

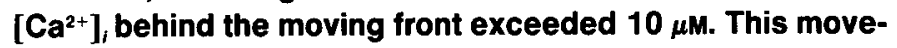
ment of $\mathrm{Ca}^{2+}$ was greatly reduced by an externally applied electrical field with the cathode distal to the lesion and was increased by an applied field of the opposite polarity. When axons were transected in $\mathrm{Ca}^{2+}$-free medium, no increases in $\left[\mathrm{Ca}^{2+}\right]_{i}$ occurred. One $\mathrm{d}$ after transection, $\left[\mathrm{Ca}^{2+}\right]_{i}$ was at or below the precut levels, except in the distal $250 \mu \mathrm{m}$, where it remained slightly elevated. Therefore, axons can survive the high levels of $\left[\mathrm{Ca}^{2+}\right]$, that occur after transection and can reestablish normal $\left[\mathrm{Ca}^{2+}\right]$; levels within $24 \mathrm{hr}$. Measurements of both the diffusion coefficient and the fluorescence polarization of fura 2 indicate that the dye is not significantly bound to axoplasmic components.

When an axon is severed, a process of degeneration occurs in both the proximal and the distal portions. This degeneration is characterized by neurofilament disarrangement and fragmentation, swollen mitochondria, disruption of microtubules, and a granular appearance of the axoplasm (Zelena et al., 1968; Kao et al., 1983). Schlaepfer and Bunge (1973) suggested that these changes are related to changes in the free-calcium concentration $\left(\left[\mathrm{Ca}^{2+}\right]_{i}\right)$ in the axon. This idea is supported by experiments on isolated axonal segments, where degeneration is reduced, or completely prevented, by chelating the extracellular calcium (Schlaepfer, 1974). Further evidence for the involvement of calcium in degeneration comes from experiments in which the $\left[\mathrm{Ca}^{2+}\right]_{i}$ is elevated with the calcium ionophore A23187. Such

\footnotetext{
Received Mar. 26, 1990; revised June 22, 1990; accepted June 28, 1990.

We thank Dr. R. B. Borgens for teaching us the isolated lamprey CNS preparation, discussing the experiments, and reviewing the manuscript. We also thank Dr. M. E. McGinnis for discussing the results and reviewing the manuscript. This research was supported by National Science Foundation Grant DCB-8702614 We thank the Showalter Fund, Purdue University, for the purchase of the videoimage processing equipment.

Correspondence should be addressed to Kenneth $\mathrm{R}$. Robinson at the above address.

a Present address: Zoology Department, University of California at Davis, Davis, CA 95616.

Copyright @ 1990 Society for Neuroscience $0270-6474 / 90 / 113564-12 \$ 03.00 / 0$
}

treatment results in an axoplasmic disintegration that is quite similar to degeneration (Schlaepfer, 1977).

It is known that the $\left[\mathrm{Ca}^{2+}\right]_{i}$ is well buffered and is maintained far below its equilibrium concentration by several different mechanisms (Nicholls, 1986). Considering the large electrochemical gradient, an increase in the $\left[\mathrm{Ca}^{2+}\right]_{i}$ is expected following injury to the axon; Meiri et al. (1983) calculated that it might reach millimolar levels in the terminal $0.5 \mathrm{~mm}$ of a cut axon. It is difficult, however, to predict what the actual $\left[\mathrm{Ca}^{2+}\right]_{\text {i }}$ distribution will be, for a number of reasons. One reason is that the membrane potential collapses following transection (Lucas et al., 1985). This depolarization will affect the driving force for calcium into the axon, the state of voltage-gated calcium channels, and the ability of the membrane to use the sodium gradient to transport calcium ions out of the cell. Another reason is that, though calcium will diffuse into the axon from the cut end, the mobility of calcium ions in axoplasm is quite limited (Chang, 1986), so it is unclear to what extent this influx of calcium ions will change the $\left[\mathrm{Ca}^{2+}\right]_{i}$. Happel et al. (1981) have measured the total calcium that accumulates in damaged axons of the mammalian spinal cord, but gave no information about the concentration or distribution of free calcium.

We have measured the $\left[\mathrm{Ca}^{2+}\right]_{i}$ in the spinal axons of sea lamprey larva using the fluorescent calcium indicator fura 2 . The spinal axons of this animal, unlike those of most other vertebrates, have the ability to regenerate after transection (Yin and Selzer, 1983). The Mauthner cells and other spinal neurons of these animals can reform functional connections, which allows the return of normal behavior patterns (Cohen et al., 1986). The proximal portions of the Mauthner axons degenerate to about $2 \mathrm{~mm}$ from the site of transection within about $5 \mathrm{~d}$ (Yin and Selzer, 1983). Borgens et al. (1980) showed that steady electrical current, partially dependent on calcium ions, enters the end of a transected sea lamprey spinal cord. They proposed that this influx might be expected to change substantially the calcium concentration inside the terminal few $\mathrm{mm}$ of the cut axon. Roederer et al. (1983) have suggested that dieback in these Mauthner axons is mediated by an influx of calcium into the cut ends, and that the effects of applied electrical fields on dieback are due to retardation or augmentation of calcium cntry by the ficld. Herc we show that applied electrical fields do indeed modulate $\mathrm{Ca}^{2+}$ movement into the axons, and that a small field of appropriate polarity can nearly eliminate the diffusion of $\mathrm{Ca}^{2+}$ into the cut end.

\section{Materials and Methods}

Averages in the text are reported as the mean \pm the SEM, unless otherwise indicated. Experiments were performed at $20^{\circ} \mathrm{C}$, unless otherwise described. Chemicals were obtained from Sigma Chemical Co. (St. Louis, MO), unless otherwise noted. In graphs of data from single experi- 

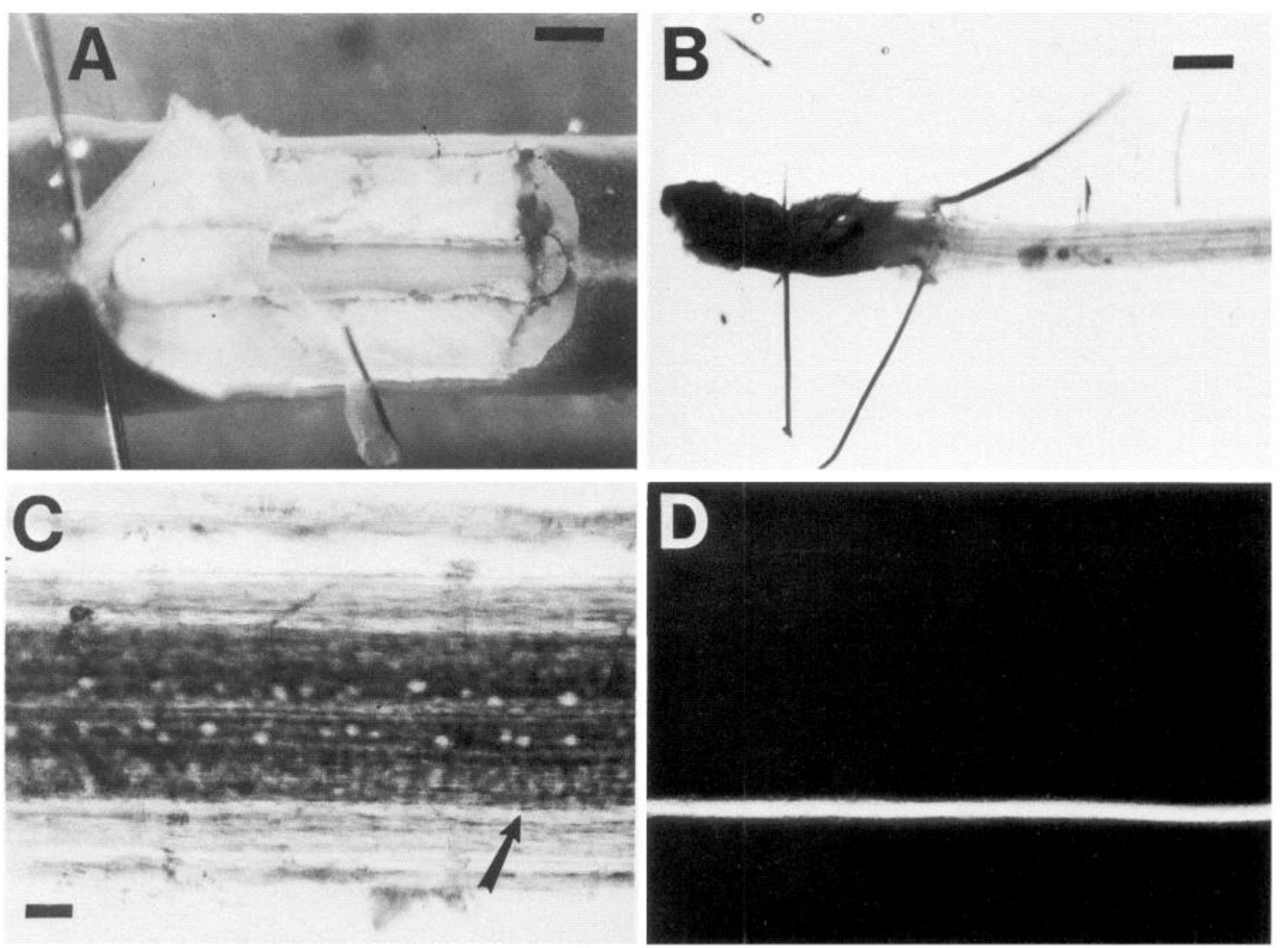

Figure 1. Preparation of lamprey spinal cord. A, Removing overlying tissues (dorsal view). Skin, muscles, fatty tissue, and dura are peeled away to the left, and the meninges layer is peeled off to the left and down. The spinal cord can be seen in the middle, with blood clots along either side. Scale bar, $1 \mathrm{~mm}$. B. Isolated brain and spinal cord pinned out in a saline-filled dish. Interneuron cell bodies are visible along the central part of the spinal cord. Scale bar, $1 \mathrm{~mm}$. $C$, Bright-field image of spinal cord. Arrow indicates a Mauthner axon, which is clearly seen near the bottom margin of the spinal cord. Muller axons and interneuron cell bodies (white spots) are also visible near the central part of the cord. Scale bar, 100 $\mu \mathrm{m}$. $D$, Fluorescence image of the injected Mauthner axon (same field as in $C$ ).

ments, each point is the mean of at least 3 ratio determinations. When more than 1 experiment is shown, each point is the grand mean of all the individual determinations. The SEM bars of a point are included in a graph only if they are larger than the symbol representing the point. Each experiment was performed on a different animal; in all experiments, 1 Mauthner axon per animal was injected and used for fluorescence measurements, while the uninjected, contralateral axon was used to determine the autofluorescence.

Animals. Larval sea lampreys (Petromyzon marinus), $10-14 \mathrm{~cm}$ in length, were obtained from the U.S. Fish and Wildlife Service, Marquette, MI. They were maintained for up to 6 months in large (115 liter) aerated aquaria at $12^{\circ} \mathrm{C}$ and fed $1 \mathrm{gm} /$ tank of baking yeast every 2 weeks. One quarter of the volume of water in each tank was removed every 2 months and replaced with filtered tap water treated with "Stress Coat" aquarium water conditioner (Aquarium Pharmaceuticals Inc., Pittsburgh, PA).

Removal of the CNS and transection of the spinal cord. The animals were anesthetized by immersion in a $0.1 \%$ solution of tricaine methanesulphonate. To remove the brain and spinal cord, a dorsal, transverse incision was made to the level of the meninges layer. This incision was opened on each side, progressing in a caudal-rostral direction. The tissues overlying the spinal cord (skin, fat, muscle, and dura) were removed, and the brain and about $6 \mathrm{~cm}$ of the spinal cord were dissected from the dura using a blunt glass probe to loosen and break the dorsal root nerves (Fig. 1A). This preparation (Fig. $1 B$ ) was pinned out in a dish filled with lamprey saline $(4 \mathrm{~mm}$ glucose, $111 \mathrm{~mm} \mathrm{NaCl}, 2.1 \mathrm{~mm}$ $\mathrm{KCl}, 1.8 \mathrm{~mm} \mathrm{MgCl}_{2}, 10 \mathrm{~mm}$ HEPES, and $2.6 \mathrm{~mm} \mathrm{CaCl} ; \mathrm{pH}, 7.40$ ). Because the CNS is not vascularized and thus exchanges nutrients and other metabolites via diffusion in vivo, this preparation remains viable in organ culture for days (Borgens et al., 1980). The Mauthner axons, which are about $40 \mu \mathrm{m}$ in diameter, are clearly visible (Fig. 1C) and can be impaled with microelectrodes. In all experiments, the caudal end of the spinal cord was cut when it was removed from the animal, but the measurements were made several $\mathrm{cm}$ from this original cut. After fura 2 was injected (described below), $\left[\mathrm{Ca}^{2+}\right]$ determinations were made on axons at several points, then the spinal cord was transected with a portion of a thin razor blade (Gillette Super Blue) near the site of fura 2 injection. Measurements were then made at the same locations as before. All measurements were made on the part of the axon that was attached to the cell body (i.e., the proximal segment).

For some 1-d experiments, the CNS was removed, injected, and transected in the dish. After about $4 \mathrm{hr}$, during which time fura 2 measurements were made, fresh oxygenated saline was added, and the preparation was left for $20 \mathrm{hr}\left(\right.$ at $\left.12^{\circ} \mathrm{C}\right)$. Fresh lamprey saline was added at 5 and $20 \mathrm{hr}$ posttransection, the CNS was returned to room temperature after about $20 \mathrm{hr}$, and fura 2 was reinjected prior to making further measurements. For most of the experiments on 1-d posttransection axons, the transection was performed in the animal (in situ). The spinal cord was exposed by making a 4-5-mm incision (rostral to caudal along the midline) in the dorsal surface of the animal. The transection was performed under a dissecting microscope at high magnification and checked visually for completeness. The wound was then held closed for approximately $5 \mathrm{~min}$ with forceps before the animal was placed in wellaerated tap water $\left(12^{\circ} \mathrm{C}\right)$ treated with Triple Sulfa (Aquarium Pharmaceuticals, Pittsburgh, PA) to reduce possible infection. After $1 \mathrm{~d}$, the brain and spinal cord were removed from the animal, and an axon was injected with fura 2 .

Microinjection of fura 2. Fura 2 was injected ionophoretically because this allows loading of specific axons and avoids problems of dye localization in organelles that may occur with AM-ester loading (Williams et al., 1985). Microelectrodes were pulled from 1.5-mm thick-walled capillary glass with filament (World Precision Instruments, Inc., New 
Haven, CT). The electrodes had about $10 \mu \mathrm{m}$ tip diameters and resistances of about $20 \mathrm{M} \Omega$. They were first back-filled with a short column of $11 \mathrm{~mm}$ fura 2 (pentapotassium salt, Molecular Probes, Eugene, OR), then filled the rest of the way with $100 \mathrm{~mm} \mathrm{KCl}$. These electrodes were used in a standard electrophysiological setup (Narishige micropositioner, WPI Model 701 amplifier, Textronix storage oscilloscope, Grass Model SD9 simulator) to impale the axon. If a membrane potential of $-60 \mathrm{mV}$ or more was observed (indicating a healthy preparation), hyperpolarizing current was applied through the electrode, which ionophoresed the negatively charged fura 2 into the axon. Square-wave pulses of $1-5 \mathrm{nA}, 100 \mathrm{msec}$ in duration, were applied at $5 \mathrm{~Hz}$ for $5 \mathrm{~min}$. We estimated the final intracellular concentration of fura 2 to be $5 \mu \mathrm{M}$ or less. The fura 2 was allowed to diffuse in the axon for $1 \mathrm{hr}$ before measurements were taken.

Photomultiplier measurements. The fluorescence at $510 \mathrm{~nm}$ was measured using a photomultiplier tube (Hamamatsu Corp., Middlesex, NJ) and photon counter (Pacific Precision Instruments, Concord, CA) coupled to a modified Leitz Dialux microscope (Cork et al., 1987) and a $36 \times$ reflecting objective (Ealing Corp.) with an $8-\mathrm{mm}$ working distance. The long working distance allowed us to work at relatively high magnification with a thick preparation that was immersed in a solution. Because this objective uses only mirrors to focus the light, it fully transmits the short-wavelength UV light (i.e., $340 \mathrm{~nm}$ ) used in our experiments. The excitation wavelength was alternated between 340 and 380 $\mathrm{nm}$ by manually switching the narrow-bandpass interference filters that were mounted on a slider. In some earlier experiments, we used a 350$\mathrm{nm}$ interference filter but changed to the $340-\mathrm{nm}$ filter because it gave a larger change in the fluorescence ratio for a given change in calcium concentration. The fluorescence at each wavelength was corrected by subtracting a background value that was obtained by measuring the fluorescence from the uninjected contralateral Mauthner axon. This background fluorescence was measured in many areas of the spinal cord, including the area near the cut end. It was nearly constant throughout the experiment and was typically between 5 and $15 \%$ of the fura 2 fluorescence from the injected axon. The region of the axon from which light was measured was restricted to a $30-\mu \mathrm{m}$ spot by placing a pinhole in the image plane of the microscope objective and a diaphragm in the excitation light path (Cork et al., 1987). This limits the depth of field from which the fluorescence is measured to about $40 \mu \mathrm{m}$ (Koppel et al., 1976).

The $\left[\mathrm{Ca}^{+2}\right]_{i}$ was determined by calculating the ratio of the corrected (described above) fluorescence with $340-\mathrm{nm}$ excitation to that with 380 $\mathrm{nm}$ excitation. These ratios were used along with ratios from $\left[\mathrm{Ca}^{+2}\right]$ standards to calculate the $\left[\mathrm{Ca}^{2+}\right]_{i}$ (Grynkiewicz et al., 1985). We determined a $K_{d}$ for fura 2 of $361 \mathrm{nM}$ using calcium-concentration standard solutions buffered with EGTA (puriss quality; Fluka, Ronkonkoma, NY). Thesc solutions contained $1.8 \mathrm{mM} \mathrm{Mg}^{2+}, 10 \mathrm{~mm}$ EGTA, $5 \mathrm{~mm}$ HEPES, $140 \mathrm{mM} \mathrm{KCl}$, and $10 \mathrm{~mm} \mathrm{NaCl}$. They were adjusted to an ionic strength of $0.15 \mathrm{M}$ and a $\mathrm{pH}$ of 7.40. The ratio method is critical for our experiments, because it renders the calcium determinations independent of variations in fura 2 concentration.

Video-image processing of fluorescence images. The video-image processing system consisted of a Nikon Diaphot TMD inverted microscope with a manually operated slider containing the excitation filters [similar to that used on the photomultiplier tube (PMT) system], a KS-1380 microchannel-plate image intensifier, a VS-2000N Newvicon camera (Videoscope International, Ltd., Herndon, VA), and the $36 \times$ reflecting objective described above. Image processing was performed with software from G. W. Hannaway and Associates (Boulder, $\mathrm{CO}$ ) running on a Sun Workstation with frame buffer, pipeline processor, and analog/ digital interface image-processing modules (Imaging Technology Incorporated, Woburn, MA).

Images of the calcium distribution in axons were generated from two 100 -frame averages of the fluorescence emission $(510 \mathrm{~nm}), 1$ at each of the excitation wavelengths of fura $2(340 \mathrm{~nm}$ and $380 \mathrm{~nm})$. All images were $511 \times 4708$-bit pixels ( 256 gray values). To collect and store 2 fluorescence images takes about $30 \mathrm{sec}$, so pairs of images were collected at various points along the cord before and after transection, and processing of images was performed later. The video images of the calcium distribution in axons are pseudocolor maps of the fura $F_{340}: F_{380}$ ratio. They were generated in the following manner: First, a 380 -nm background image, the 510-nm fluorescence of an uninjected part of the spinal cord illuminated with 380-nm light, was subtracted from the 380$\mathrm{nm}$ axon fluorescence image. Then, a $340-\mathrm{nm}$ background was subtracted from the raw $340-\mathrm{nm}$ image, and the resulting image was divided by the $380-\mathrm{nm}$ background-subtracted image on a pixel-by-pixel basis. To maintain the most accuracy in the ratio images, all of the raw fluorescence images and background images were recorded at different gain settings on the image intensifier. For each image, the gain was set so that the brightest parts of the image had a gray value of just under 255 . During production of the ratio images, background images were scaled to the same gain as the raw fluorescence images, and the ratio image was multiplied by a scaling factor to account for the difference in the gains between the $340-\mathrm{nm}$ and $380-\mathrm{nm}$ background-subtracted images. The ratio image was also scaled so that the range of ratio values in the image was between 0 and 255 and occupied as much of the gray scale as possible.

As a result of inaccuracies in the background subtraction process, there was usually some background noise in the final ratio images. To clarify the final images, this noise was masked by subtracting an image derived from one of the raw fluorescence images (usually the $380-\mathrm{nm}$ one). The end result of this masking procedure was to display only those portions of the ratio image that were derived from areas of the raw fluorescence images with gray-scale values about a predefined thrcshold, that is, where the fluorescence signal from the axon was much greater than the background.

To illustrate the distributions of calcium, the ratio images were displayed in pseudocolor. Different colors were assigned to selected ranges of ratios. Because only a limited number of colors were distinguishable in the final photographic prints, we worked with a reduced number of colors and shifted the color scale depending upon which range of calcium values was considered important for the image.

Values of the minimum and maximum ratios were obtained from images of droplets of calcium buffers containing $2 \mu \mathrm{M}$ fura 2 . The ratioscaling factor (Grynkiewicz et al., 1985) for the video fluorescence system was also determined from these images, as was a value for the $K_{d}$ of fura 2 . All of these values were used in the calculation to convert ratios to calcium concentrations (Grynkicwicz ct al., 1985).

Fluorescence polarization methods. We modified our photomultiplierequipped fluorescence microscope for steady-state fluorescence polarization studies. A Glan-Thompson UV polarizer was mounted in the excitation-light path so that the electric component of the exciting light was polarized parallel to the dichroic mirror. A second polarizer was mounted in the emission path in such a way that its polarizing direction could be rotated to be either parallel or perpendicular to the direction of polarization of the exciting light. Because the transmittance of a dichroic mirror would be expected to be polarization dependent, we measured the transmittance of the emission path (including the microscope objective, the dichroic mirror, and the barrier filter) to light polarized in the 2 directions of interest and derived an instrument-correction factor for the fluorescence-polarization measurements. For our particular arrangement, wc found that light polarized parallel to the dichroic mirror was transmitted by the emission-side optics 0.459 times as well as light polarized perpendicular to that direction. For actual measurements on fura 2 , a $380 \pm 10-\mathrm{nm}$ excitation filter, a $25 \times$ waterimmersion objective, and a 495 -nm-long pass-emission filter were used. A fura 2-loaded axon or an aqueous solution containing fura 2 was excited and the emission intensity in the 2 polarization directions recorded by the photon-counting system. After applying the instrument correction factor, the anisotropy, $A$, was calculated according to the equation $A=\left(I_{-}-I_{1}\right) /\left(I_{=}+2 I_{1}\right)$ (Cantor and Schimmel, 1980), where $I_{-}$is the intensity of the emitted light polarized parallel to excitation light, and $I_{1}$ is the intensity of the emitted light polarized perpendicular to the excitation light. The maximum value for $A$ for a totally rigid system is 0.4 . At the other extreme, if the fluorescent molecule is unconstraincd on the time scalc of the lifetime of the excited state, $A=0$

Diffusion coefficient of fura 2 . We ionophoretically injected fura 2 into the axon for $5 \mathrm{~min}$ at a marked location. We then measured the fluorescence at selected distances away from the site of injection using a $360 \pm 5-\mathrm{nm}$ excitation filter. The fluorescence was measured by the PMT at each location for only $12 \mathrm{sec}$ to minimize photobleaching. At various times following the injection, we again measured the distribution of fura 2. $D_{f}$ was calculated from the equation

$$
C=0.5 \sum_{i=1}^{n} C_{i}\left\{\operatorname{erf}\left(\frac{x-h_{2 i}}{2\left(D_{f} t\right)^{0.5}}\right)+\operatorname{erf}\left(\frac{x-h_{1 i}}{2\left(D_{f} t\right)^{0.5}}\right)\right\},
$$

where $C$ was the concentration of the diffusing substance, with diffusion coefficient $D_{f}$, at time $t$ and distance $x$. The initial distribution was divided into $n$ regions of concentration $C_{i}$, and each region had upper 
and lower bounds $h_{1 i}$ and $h_{2 i}$, respectively (Timmerman and Ashley, 1986). The initial distribution was determined within $10 \mathrm{~min}$ of injection and included an area of about $2 \mathrm{~mm}$ on either side of the injection site.

Each of the fura 2 distribution curves was fit to the equation using a least-squares method and the first set of fluorescence values as the initial distribution. This is similar to the method used by Timmerman and Ashley (1986) to determine the $D_{f}$ for fura 2 in free solution, except that they injected the fura 2 into the open end of a glass capillary.

Reduced external $\left[\mathrm{Ca}^{2+}\right]$. Five mM EGTA (Fluka) was added to, and $\mathrm{CaCl}_{2}$ was omitted from, the normal lamprey saline. This lowered the free $\left[\mathrm{Ca}^{2+}\right]$ in the saline to below $1 \mathrm{~nm}$. Additional $\mathrm{MgCl}_{2}$ was added $(2.6 \mathrm{~mm})$ to maintain an approximately normal concentration of divalent cations. Measurements of the $\left[\mathrm{Ca}^{2+}\right]_{i}$ were taken at various locations before the low-[Ca $\left.{ }^{2+}\right]$ saline (LCS) was added to the dish. The solution in the culture dish was exchanged 3 times with LCS, and the CNS was soaked for $1 \mathrm{hr}$. After another exchange of solution, the restinglevel measurements were taken. After these measurements, the spinal cord was transected, and periodic measurements at several locations were begun.

Membrane-potential measurements. In order to measure the spatial variation in the resting potential of cut axons, impalements were made at different locations. The electrodes used for these measurements were identical to those used for the fura 2 injections, except that they were filled with $3 \mathrm{M} \mathrm{KCl}$. All measurements were taken within $1 \mathrm{hr}$ after transection.

Application of electrical fields. Isolated spinal cords were pinned into saline-filled rectangular troughs $(1.6 \mathrm{~mm}$ wide, $1.6 \mathrm{~mm}$ deep) in Sylgardfilled chambers (see Fig. 7). The troughs were closed by laying coverslips (6 cm long) over the open upper surfaces. The coverslips were in place during all fura 2 measurements and electrical field applications, but could be removed for fura 2 microinjection and spinal-cord transection. Electrical contact with the troughs was made via agar bridges terminating in baths containing $\mathrm{Ag}-\mathrm{AgCl}$ electrodes; these electrodes were connected to a constant-current source (Robinson, 1989). Two such chambers were used for each experiment; no current was applied to 1. Both chambers could be mounted on the stage of the photomultiplierbased fura 2 measuring system. After injection of fura 2 into 1 Mauthner axon of each cord, $\left[\mathrm{Ca}^{2+}\right]_{i}$ in the axons was measured, the cords were transected, and the electrical current was turned on within $1 \mathrm{~min}$ of transection. The actual electrical field produced by the current was determined by measuring the voltage difference between the 2 ends of the coverslip; these measured fields agreed closely with the fields expected for the currents and the calculated resistances of the troughs. The medium in the chambers was changed periodically throughout the experiment.

\section{Results}

\section{Basal $\left[\mathrm{Ca}^{2+}\right]$}

We removed the brains and spinal cords from the animals (Fig. $1 A$ ) and placed them in saline-filled dishes (Fig. $1 B$ ). A Mauthner axon was then ionophoretically injected with fura 2 (Fig. $1 C$ ), and $\left[\mathrm{Ca}^{2+}\right]_{i}$ was determined using the dual-wavelength ratio method described by Grynkiewicz et al. (1985). We found that the basal $\left[\mathrm{Ca}^{2+}\right]_{i}$ in intact axons was $44 \pm 3 \mathrm{nM}(n=22)$. We determined a calcium dissociation constant $\left(K_{d}\right)$ for fura 2 of $361 \mathrm{~nm}$ in solutions that closely matched the intracellular ionic milieu and temperature of our preparation. We have used this $K_{d}$ for all of our calculations of $\left[\mathrm{Ca}^{2+}\right]_{i}$. To investigate the possibility that isolating the CNS changed the $\left[\mathrm{Ca}^{2+}\right]_{i}$, we injected fura 2 into an axon after completing only half of the isolation procedure; that is, we removed all of the overlying tissues but lcft the CNS in the animal. We then placed the entire animal on the stage of the microscope and measured the $\left[\mathrm{Ca}^{2+}\right]_{i}$ at several places along the axon; this was possible because of the long working distance of the reflecting objective. In 1 such experiment, we found that the $\left[\mathrm{Ca}^{2+}\right]$, in the axon was $55 \pm 9 \mathrm{nM}$ (mean $\pm \mathrm{SD}, n=7$ ). After removing the CNS, the $\left[\mathrm{Ca}^{2+}\right]_{i}$ was $65 \pm 10 \mathrm{~nm}(n=10)$ in the same area. We do not consider these values to be significantly different $(P=0.061,2$-tailed $t$ test).
A

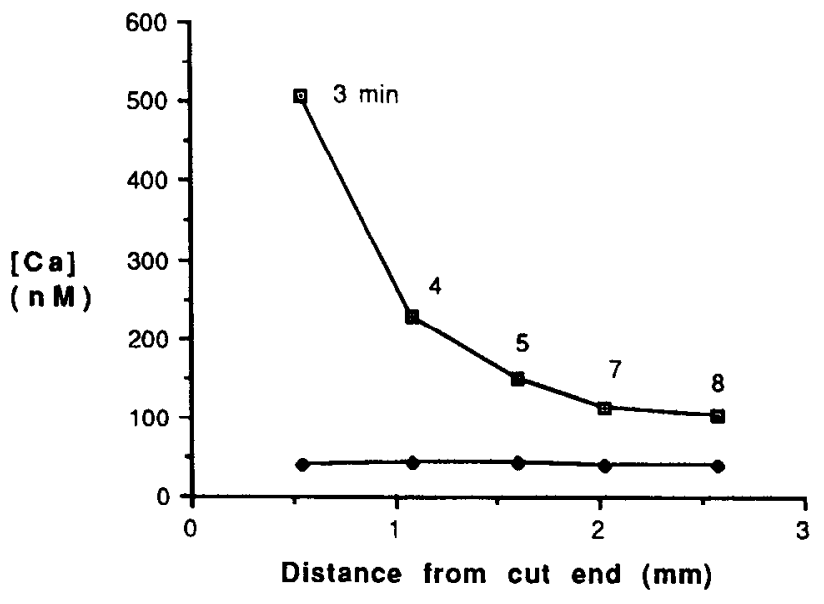

B

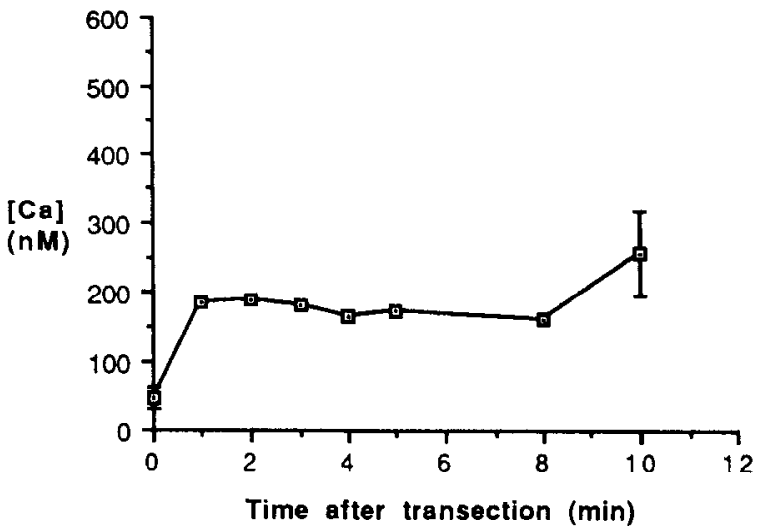

Figure 2. Rapid changes in $\left[\mathrm{Ca}^{+2}\right]_{i}$ following transection. Each data point is the mean value from 3 experiments on different animals. $A$, Gradient in the end of an axon following transection. The numbers next to each point indicate the mean time following transection. The lower line is the mean value of $\left[\mathrm{Ca}^{+2}\right]_{i}$ in the same locations prior to cutting. Beyond $2.6 \mathrm{~mm}$, the fura 2 concentration was too low to give reliable values. $B$, Change in $\left[\mathrm{Ca}^{+2}\right]_{i}$ at $1.53 \mathrm{~mm}$ from the cut end of the spinal cord as a function of time after transection.

\section{Changes in $\left[\mathrm{Ca}^{2+}\right]_{\mathrm{i}}$ following transection}

Figure $2 A$ shows the distribution of $\left[\mathrm{Ca}^{2+}\right]_{i}$ in the proximal segments of Mauthner axons immediately after transection. $\left[\mathrm{Ca}^{2+}\right]_{\text {i }}$ was elevated for at least $2.5 \mathrm{~mm}$ up the axon from the cut; at $0.54 \mathrm{~mm}$, the $\left[\mathrm{Ca}^{2+}\right]_{i}$ was 14 times greater than the resting level, and at $2.54 \mathrm{~mm}$, it was 3 times greater. These measurements were taken in sequence from the cut end, with the result that the determinations at $2.54 \mathrm{~mm}$ were not taken until about 8 min after transection. As shown in Figure $3 B$, the steepness of the spatial gradient of $\left[\mathrm{Ca}^{2+}\right]_{i}$ increased with time. The distances indicated above were measured from the cut end of the spinal cord. The exact location of the end of the axon is uncertain because of retraction or disintegration; however, we have ob- 
A

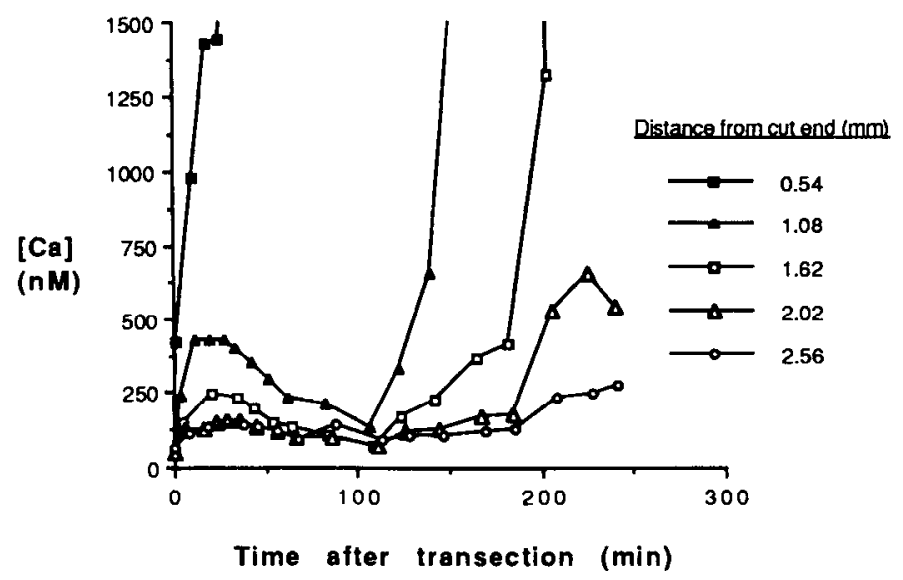

B

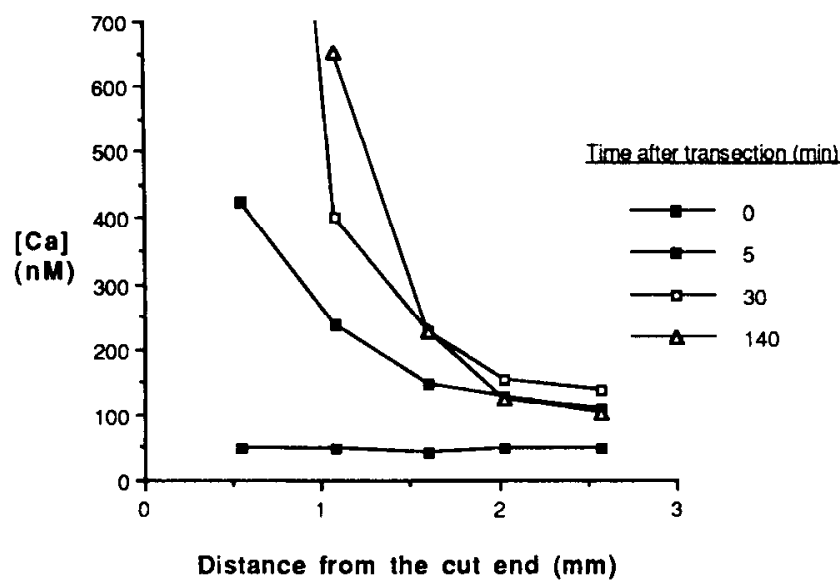

Figure 3. Longer-term changes in $\left[\mathrm{Ca}^{+2}\right]_{i}$. The data points are representative of 4 separate experiments. $A,\left[\mathrm{Ca}^{+2}\right]_{i}$ as a function of time after transection. Each line connects values measured at the indicated distance from the cut end. After $4 \mathrm{hr}$, the fura 2 concentration became too low to give reliable values. $B$, Replot of data in $A$, showing the change in the $\left[\mathrm{Ca}^{+2}\right]_{i}$ gradient over time.

served fluorescence within $50 \mu \mathrm{m}$ of the cut immediately after transection and assume that the end of the axon is at about this distance.

By measuring the $\left[\mathrm{Ca}^{2+}\right]_{i}$ at a single distance, better time resolution was obtained. At $1.53 \mathrm{~mm}$ from the cut end, the $\left[\mathrm{Ca}^{2+}\right]_{i}$ increased within 2 min and remained at about the same concentration for the next 7 min (Fig. 2B). Following this initial rapid rise, there was a second phase of calcium changes during which the $\left[\mathrm{Ca}^{2+}\right]_{i}$ rose slowly for about $20 \mathrm{~min}$, then gradually declined (Fig. $3 A$ ). While this slow rise occurred at about the same time throughout all of the terminal portion of the axon, the peak of the increase was smaller at points further from the cut end. The second phase was not seen at points near the plane of transection (e.g., $0.54 \mathrm{~mm}$ in Fig. $3 A$ ) because it was obscured by a third phase.

The third phase consisted of a moving front of calcium ions, originating at the cut end and progressing up the axon over time. $\left[\mathrm{Ca}^{2+}\right]_{i}$ increased to levels greater than those that can be measured reliably by fura 2 (about $10 \mu \mathrm{M}$ ). This was the only 1 of the 3 phases that occurred at different times at different locations. It was evident at $0.54 \mathrm{~mm}$ within 20 min after transection, but was not detected at $1.62 \mathrm{~mm}$ until $3 \mathrm{hr}$ later. It did not extend beyond about $2 \mathrm{~mm}$ from the plane of transection within the 4-hr measuring period (Fig. $3 A$ ). In 2 experiments, measurements at about $2 \mathrm{~mm}$ from the plane of transection were made for up to $8.5 \mathrm{hr}$ after transection, and the $\left[\mathrm{Ca}^{2+}\right]_{i}$ did not increase further than that shown in Figure $3 A$ (data not shown).

The measurements described above were performed using a PMT-based system in which spatial resolution was achieved by placing a pinhole in the image plane of the objective lens, thus restricting the origin of the light detected to a small region of the axon. The distribution of $\left[\mathrm{Ca}^{2+}\right]_{i}$ was then determined by moving the preparation so that different regions were monitored through the pinhole. Measuring the $\left[\mathrm{Ca}^{2+}\right]_{i}$ in this way, however, limits the temporal resolution, so we used a video-image processing system to provide a more complete picture of the spatial and temporal distribution of the $\left[\mathrm{Ca}^{2+}\right]_{i}$ changes. We have performed 5 experiments using the video-image processing system where we looked at the changes in the $\left[\mathrm{Ca}^{2+}\right]_{i}$ immediately after transection; Figure 4 is representative of the images we obtained. The $\left[\mathrm{Ca}^{2+}\right]_{i}$ in a segment of an axon before transection is shown in Figure $4 A$. The gradient that was established immediately following transection is shown in Figure $4 B$. There was a steep gradient at about $400 \mu \mathrm{m}$ from the cut end of the spinal cord, where the $\left[\mathrm{Ca}^{2+}\right]_{i}$ dropped from above $4 \mu \mathrm{M}$ to around $600 \mathrm{nM}$ in a distance of $200 \mu \mathrm{m}$. At about $2 \mathrm{~mm}$ from the cut end, the $\left[\mathrm{Ca}^{2+}\right]_{i}$ was about 3-fold higher than precut levels. After $40 \mathrm{~min}$, the front of $\mathrm{Ca}^{2+}$ had progressed up the axon to about $1.2 \mathrm{~mm}$ (Fig. $4 C^{2}$ ). At $2.0 \mathrm{~mm}$, the $\left[\mathrm{Ca}^{2+}\right]$, was higher than it had been 40 min earlier (cf. last images in Fig. $4 B, C$ ). At this level of resolution, we observed no compartmentalization of the fura 2 in the cytoplasm.

The spatial distribution inferred from the PMT data agrees well with that seen with the video system. Average ratio values were taken from the video images at selected distances, and Figure 5 shows these data plotted on the same axes as in Figure $3 B$. The video images (Fig. $4 B, C$ ) show fluorescence nearer to the cut end than do the results shown in Figure 3B. This is because we chose to record information only from set distances in Figure $3 B$, and $0.5 \mathrm{~mm}$ was the closest distance where we could obtain reliable data over several time points. Closer to the cut end, the fura 2 signal quickly disappeared following transection, probably because fura 2 leaked out of the open end of the axon. The effect of this leakage was also evident in the video images (cf. first images in Fig. 4B,C).

\section{Mechanisms of transection-induced changes in $\left.\mathrm{Ca}^{2+}\right]_{\text {i }}$}

To explore the sources of the changes in $\left[\mathrm{Ca}^{2+}\right]_{i}$ that occur following transection, we performed 2 types of experiments to alter the movement of calcium from the bathing medium into the axon: we lowered the external $\left[\mathrm{Ca}^{2+}\right]$ before cutting the axon, and we applied electrical fields to the cut axon. 


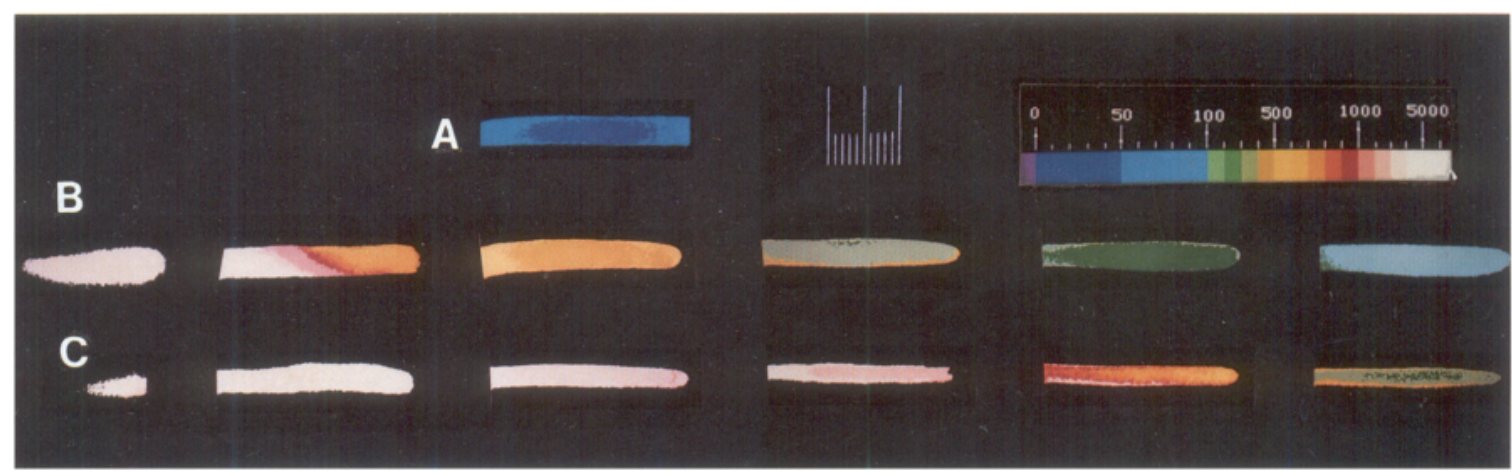

Figure 4. Visualization of distribution of $\left[\mathrm{Ca}^{+2}\right]_{i}$ using video-image processing system. $A,\left[\mathrm{Ca}^{+2}\right]_{i}$ in a representative segment before transection. The variation in the apparent $\left[\mathrm{Ca}^{2+}\right]_{i}$ of this segment is assumed to be due to inaccuracies in the background subtraction or nonunifom videocamera gain and illumination, rather than any differences in the axonal $\left[\mathrm{Ca}^{2+}\right]_{i}$. The $\left[\mathrm{Ca}^{2+}\right]_{i}$ is about $55 \pm 15 \mathrm{nM}$. B, $\left[\mathrm{Ca}^{+2}\right]_{i}$ distribution immediately after transection. Each image was taken in sequence, starting at the left (nearest the cut, farthest from the cell body) and progressing cranially, with a $90-\mu \mathrm{m}$ gap between each image. The cut end of the spinal cord is approximately $60 \mu \mathrm{m}$ from the tip of the left-most image. The left-most image was taken $7 \mathrm{~min}$, and the right-most was taken $14 \mathrm{~min}$, after the transection. $C,\left[\mathrm{Ca}^{+2}\right]_{i}$ distribution starting at 30 min after transection. The sequences in $B$ and $C$ are aligned so that the position of the cut end of the spinal cord is approximately the same in each series. White values are above the saturating level for fura 2. The distance scale is an image of an objective micrometer slide at the same magnification as the color images; each division is $10 \mu \mathrm{m}$. The color scale in the upper right shows the correspondence between $\left[\mathrm{Ca}^{2+}\right]_{i}$ in nM and the colors used in the images.

When the CNS was immersed in LCS, the resting $\left[\mathrm{Ca}^{2+}\right]_{i}$ in the axons declined from $41 \pm 15 \mathrm{~nm}$ to $9 \pm 18 \mathrm{~nm}$. Apparent $\left[\mathrm{Ca}^{2+}\right]_{i}$ values less than 0 were measured at some locations in the axon. This may be due to a difference in fura 2's in vivo properties, compared to our in vitro calibrating conditions, or it may simply reflect the fact that fura 2 is not a very sensitive $\mathrm{Ca}^{2+}$ indicator at these extremely low concentrations. In any case, it is clear that calcium is lower in axons bathed in LCS than in normal lamprey saline. After transection, there were no significant increases in $\left[\mathrm{Ca}^{2+}\right]_{i}$ during the subsequent 4 -h period (Fig. 6). In some cases, the $\left[\mathrm{Ca}^{2+}\right]_{i}$ declined to a lower concentration than before transection.

The contributions of calcium electrophoresis and diffusion to the observed calcium changes were assessed by measuring the calcium levels in axons in cords pinned into specially designed chambers that allowed electrical fields to be applied to them (Fig. 7). We found that an electrical current in the rostral-caudal

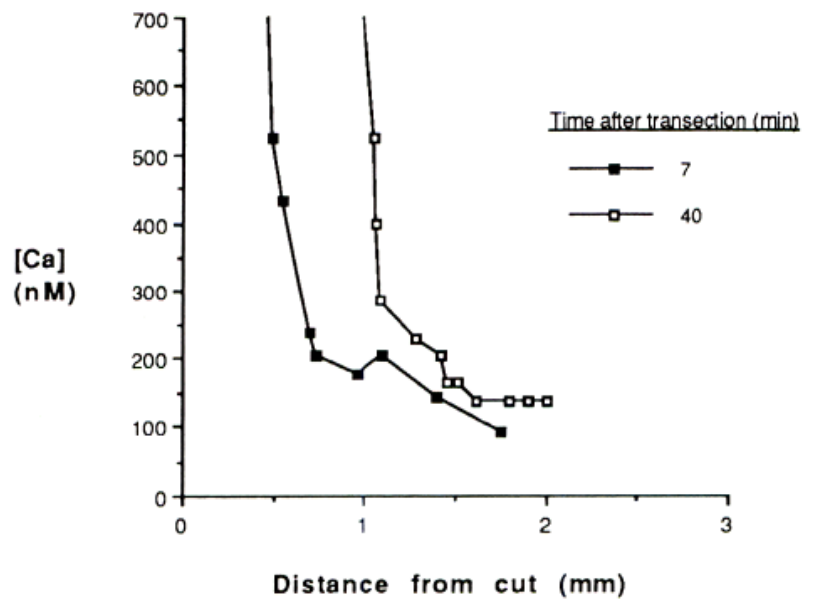

Figure 5. Distribution of $\left[\mathrm{Ca}^{+2}\right]_{i}$ derived from images in Figure $4, B$ and $C$. Each data point is the average of pixel values sampled from an area $10 \mu \mathrm{m}$ in diameter centered on the distances indicated. This average was converted to a calcium concentration using the calcium-concentration standard determinations used to generate the color scale. Each line connects points from the sequence of images beginning at the time indicated. direction profoundly altered the third phase of calcium changes following transection. At a field strength of $10 \mathrm{mV} / \mathrm{mm}$, this third phase was essentially eliminated (Fig. 8). This effect was dependent on both the magnitude and the direction of the applied field. In order to characterize these effects, we have defined a quantity that we call the penetration distance (PD). The PD is a measure of the greatest distance from the cut end of the axon that a given $\left[\mathrm{Ca}^{2+}\right]_{i}$ can be found $4 \mathrm{hr}$ after transection; thus, PD-1 and PD-5 are the greatest distances from the site of the cut that $1 \mu \mathrm{M}$ and $5 \mu \mathrm{M}\left[\mathrm{Ca}^{2+}\right]_{i}$, respectively, are measured at $4 \mathrm{hr}$. Shown in Figure 9 are the effects of field strength and polarity on PD-1 and PD-5. We also noted that rostral-caudal fields caused the axons to retain fura 2 near the site of transection longer than untreated controls. This is to be expected for a negatively charged molecule, but it has no effect on the ability to measure $\left[\mathrm{Ca}^{2+}\right]_{i}$, because the ratio method we used is independent of the dye concentration.

We were also interested in measuring the endogenous electrical field that results from the graded depolarization of the axon because of transection. Wicklegren et al. (1985) measured this in adult lamprey axons, but there are no data for larval axons. We measured the membrane potential by impaling the axons at different positions with glass microelectrodes. The results are shown in Figure 10; there is a field of $10-20 \mathrm{mV} / \mathrm{mm}$

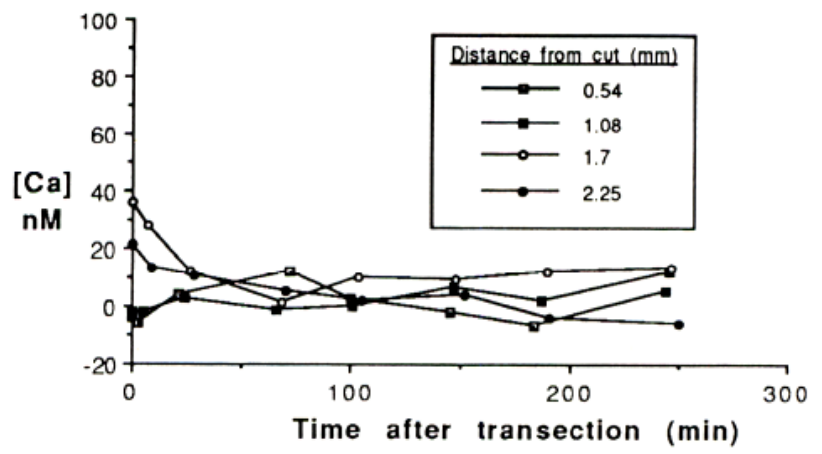

Figure 6. Effect of low extracellular $\left[\mathrm{Ca}^{2+}\right]$ on changes in $\left[\mathrm{Ca}^{2+}\right]_{i}$. Each line connects values measured at the indicated distance (in $\mathrm{mm}$ ) from the cut end. Data are from 1 of the 2 experiments. 


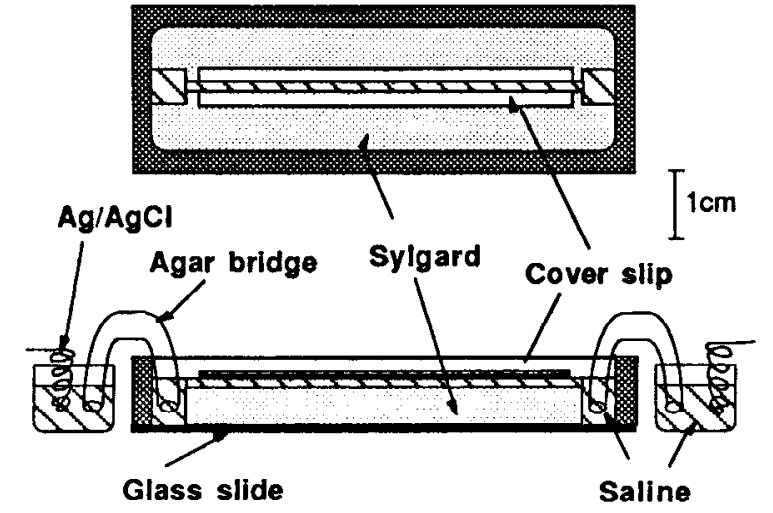

Figure 7. Diagram of chamber used to apply electric fields. The slot in the Sylgard is just wide enough to accommodate a pinned spinal cord. During fura 2 ratio measurements, 2 such chambers were placed on the stage of the microscope. One chamber was the 0-current control; the other one contained a spinal cord that had current passed through it.

in the distal $1 \mathrm{~mm}$ of the axons. For technical reasons, we were unable to measure the change in this endogenous field as a result of the applied field, but we assume that applied fields are uniform and additive to the endogenous field.

\section{Distribution of $\left[\mathrm{Ca}^{2+}\right], 1$ after transection}

We measured the calcium distribution $1 \mathrm{~d}$ after transection, when a new membrane has formed over the cut end (Clark and Wickelgren, 1982). We found that the end of the axons, as indicated by the abrupt end of the fluorescence, was $293 \pm 48$ $\mu \mathrm{m}(n=17)$ from the cut end of the spinal cord. Throughout most of the distal $2 \mathrm{~mm}$ of these axons, the $\left[\mathrm{Ca}^{2+}\right]_{i}$ was at or below precut levels. In some regions, we determined ratios that were below those measured from in vitro standards for $0\left[\mathrm{Ca}^{2+}\right]_{i}$; this resulted in apparent negative values for $\left[\mathrm{Ca}^{2+}\right]_{i}$. Figure $11 \mathrm{~A}$ shows that an axon that had high $\left[\mathrm{Ca}^{2+}\right]_{i}$ after transection (Fig. $3 B$ ) had subbasal levels of $\left[\mathrm{Ca}^{2+}\right]_{i}$ in the same locations $1 \mathrm{~d}$ later. $\left[\mathrm{Ca}^{2+}\right]_{i}$ was slightly elevated in the most distal $0.25 \mathrm{~mm}$ of the axon, though its level was far below that found in the same regions shortly after transection (cf. Figs. $3 B, 11 A$ ). This same pattern was seen both in spinal cords that were transected in the dish and maintained in culture overnight (Fig. 11A) and in spinal cords that were severed in the animal and removed the following day for measurement (Fig. $11 B$ ). The slight elevation

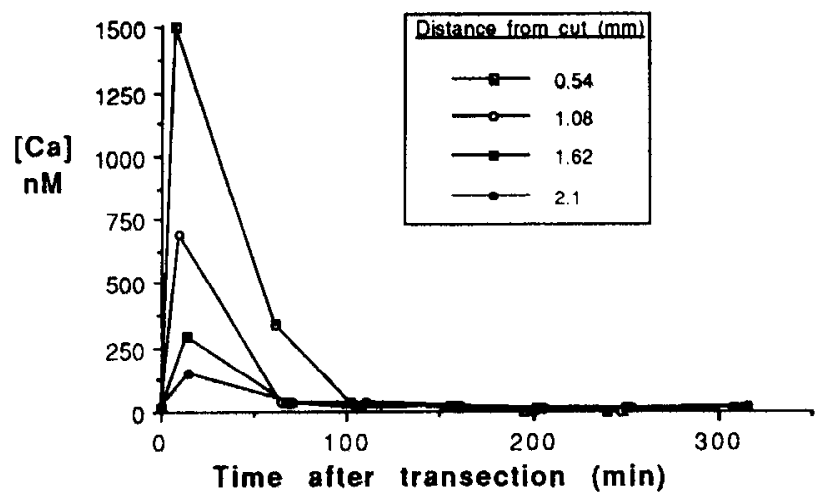

Figure 8. Changes in $\left[\mathrm{Ca}^{2+}\right]_{i}$ as function of time after transection in presence of $10 \mathrm{mV} / \mathrm{mm}$ rostral-caudal electrical field. Each line connects values measured at the indicated distances from the cut end. Shown here are the results of 1 of 5 such experiments; these experiments are summarized in Figure 9.

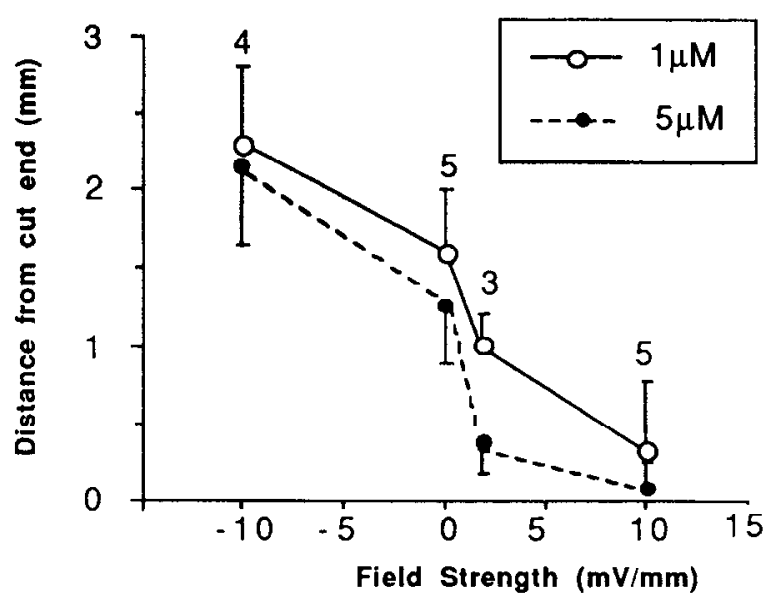

Figure 9. Modulation of penetration of $\mathrm{Ca}^{2+}$ by applied electrical fields. From data such as those shown in Figure 8, the PD of a certain level of $\mathrm{Ca}^{2+}$ at $4 \mathrm{hr}$ after transection was determined. PD-1 is the greatest distance up the axon from the cut end that $1 \mu \mathrm{M} \mathrm{Ca}{ }^{2+}$ was measured at $4 \mathrm{hr}$; PD-5 is the similar distance for $5 \mu \mathrm{M} \mathrm{Ca}{ }^{2+}$. Each data point is the mean of the number of experiments shown near the point. Error bars indicate the SD. A positive electrical field is one in the rostral-caudal direction, while a negative field is of the opposite polarity.

near the tip of the resealed axon was clearly seen when these axons were examined using the video-image processing system. The video system confirmed that the ratio values just behind the elevated portion are very low, often below that determined for $0\left[\mathrm{Ca}^{2+}\right]$ from the standard solutions. Of the 5 experiments we have performed on $1-\mathrm{d}$ distributions, we show the results from 3 in Figure 12. The distribution of $\left[\mathrm{Ca}^{2+}\right]_{i}$ in these axons was variable, and the amount of elevation at the tip ranged from high (Fig. 12A) to almost none (Fig. 12C). The most commonly observed distribution of free-calcium concentration was intermediate between these 2 extremes and is shown in Figure $12 B$.

\section{Calibration of fura 2}

Because our basal level of $\left[\mathrm{Ca}^{2+}\right]_{i}$ was somewhat lower than that reported for other neurons (Pumain, 1988), we investigated 2 possible sources of error in our calculations of the $\left[\mathrm{Ca}^{2+}\right]_{i}$. As

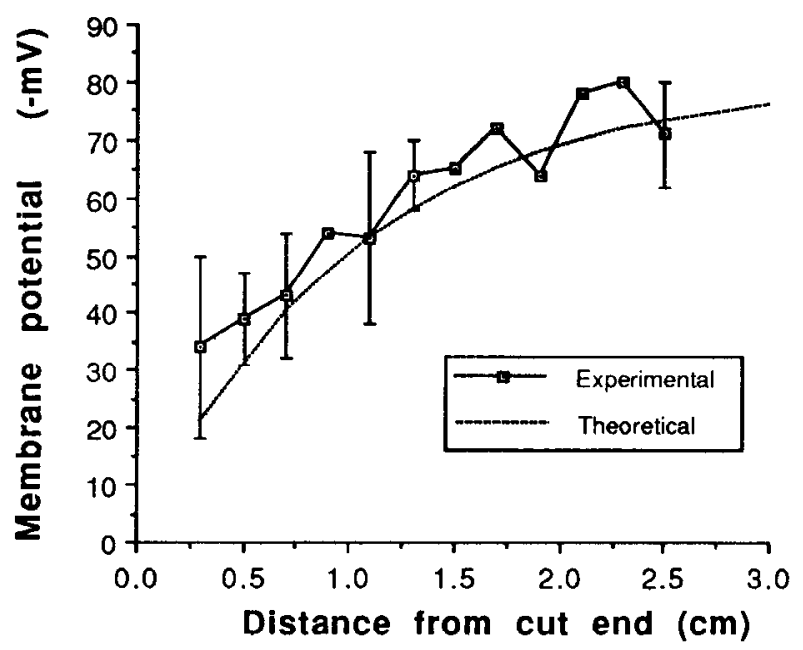

Figure 10. Membrane potential in axons following transection. Al measurements were taken within $1 \mathrm{hr}$ after the axons were cut. These data are from 4 experiments; SD bars are shown for points that are averages of more than 2 experiments. All locations were not sampled in all experiments. The theoretical curve was generated from the cable equation using a length constant of $4 \mathrm{~mm}$. 
already mentioned, we determined a $K_{d}$ more appropriate to the intraaxonal conditions than that determined by Grynkiewicz et al. (1985), but a second possible source of error was suggested by recent reports that have described the effects of viscosity on fura 2's spectra (David-Dufilho et al., 1988; Konishi et al., 1988). We measured the fluorescence polarization of fura 2 in axons and compared it to that in calcium-buffered standard solutions. We found that the $A$ (the anisotropy, a steady-state measure of the fluorescence polarization) of fura 2 was $0.109 \pm 0.001(n=$ $13)$ in our calcium buffers and $0.144 \pm 0.004(n=11)$ in the axon. When polyvinylpyrrolidone (PVP-40, Sigma Chemical Co.) was used to increase the viscosity of our calcium-calibration solutions from the original 1 centipoise $(\mathrm{cP})$ to $2 \mathrm{cP}$, a typical cytoplasmic value (David-Dufilho et al., 1988), $A$ increased to $0.156 \pm 0.004(n=6)$. Because this was similar to the value in the axon, we concluded that the increased value of $A$ in the axoplasm could be explained by the presumed higher viscosity of axoplasm, and that there was no need to invoke intracellular binding to proteins or other components (Konishi et al., 1988). We further tested this idea by determining the diffusion coefficient $\left(D_{f}\right)$ for fura 2 in the axon. The $D_{f}$ in the axon was 2.11 $\times 10^{-6} \mathrm{~cm}^{2} / \mathrm{sec}$; this is about half the value of $5 \times 10^{-6} \mathrm{~cm}^{2} /$ sec reported for fura 2 in aqueous solution (Timmerman and Ashley, 1986). According to the Stokes-Einstein equation (Cantor and Schimmel, 1980), the diffusion coefficient is inversely proportional to the viscosity, so doubling the viscosity would halve $D_{f}$. Thus, significant binding of fura 2 to intracellular components does not seem to occur in lamprey axons.

When we calibrated the fura 2 ratios with calcium standards whose viscosity was increased to $2 \mathrm{cP}$ with PVP, we found that the mean level for $\left[\mathrm{Ca}^{2+}\right]_{i}$ in uncut axons changed from 44 to $55 \mathrm{~nm}$. We have not corrected our data for this minor viscosity effect because the exact viscosity of lamprey axoplasm is not known.

\section{Discussion}

We have determined a value of $44 \mathrm{~nm}$ for the resting level of $\left[\mathrm{Ca}^{2+}\right]_{i}$ in uncut lamprey axons. This is somewhat lower than that found in other systems (Pumain, 1988), but is still within the range of values reported for axons. For example, Dipolo et al. (1976) measured a value of $20 \mathrm{~nm}$ in squid axons using aequorin and arsenazo III, but they measured a value of 106 nM using calcium-sensitive microelectrodes (Dipolo et al., 1983). Nevertheless, we considered the possibility that the $\left[\mathrm{Ca}^{2+}\right]$, values we observed are reduced by calibration artifacts. We initially used the method and equation published by Grynkiewicz et al. (1985) to calibrate the fura 2 fluorescence ratios; we determined values for the minimum ratio $\left(R_{\min }\right)$, maximum ratio $\left(R_{\max }\right)$, and scaling factor from buffered calcium-concentration standards. Using this method, we measured very low and sometimes negative $\left[\mathrm{Ca}^{2+}\right]$, values in axons under various conditions. Because others have suggested values for the $K_{d}$ of fura 2 (Timmerman and Ashley, 1986; Konishi et al., 1988) different from the 224 nM published by Grynkiewicz et al. (1985), we made a determination based on buffered calcium solutions. Our value of 361 nM was higher than that of Grynkiewicz et al. (1985) but lower than those of both Konishi et al. (1988) and Timmerman and Ashley (1986). Using this $K_{d}$ raised our calculated $\left[\mathrm{Ca}^{2+}\right]_{i}$ in resting axons closer to those that have been previously reported but had no effect on ratio values that fell below $R_{\text {min }}$. Such low ratios may simply result from uncertainties in the measurements, because the emission intensity at $340 \mathrm{~nm}$ is quite small
A

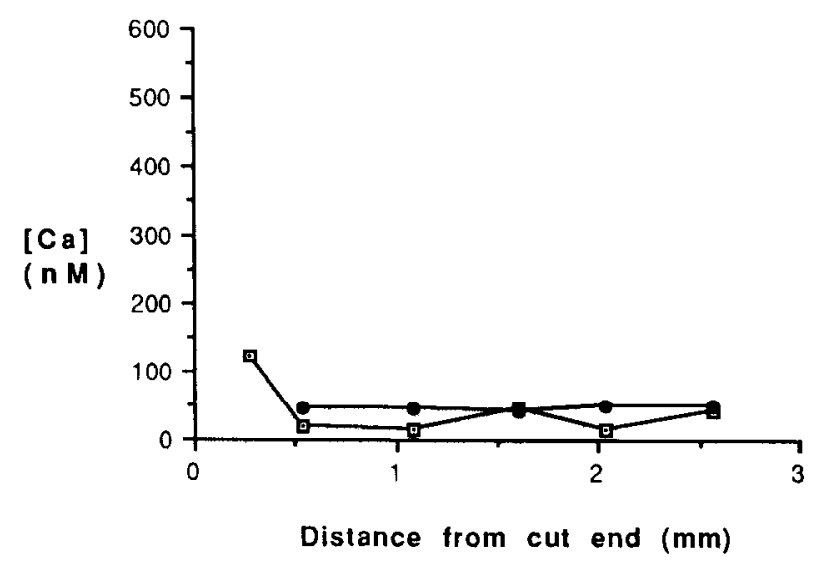

B

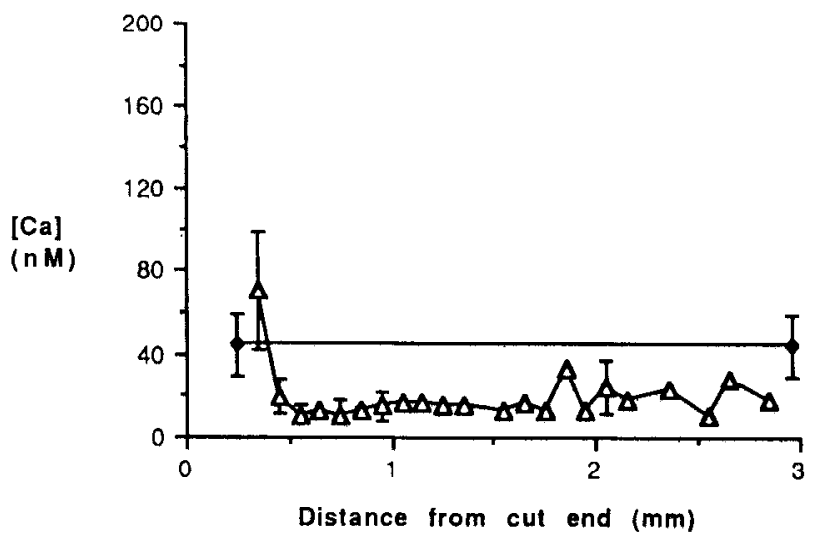

Figure 11. Distribution of $\left[\mathrm{Ca}^{+2}\right]_{i}$ in axons $1 \mathrm{~d}$ after transection. $A$, $\left[\mathrm{Ca}^{2+}\right]_{i}$ in the same axon as shown in Figure $3,1 \mathrm{~d}$ after transection (open squares). The solid points and line represent the mean $\left[\mathrm{Ca}^{+2}\right]_{i}$ in the axon before cutting. The end of the axon, as indicated by the abrupt end of fluorescence, was $0.25 \mathrm{~mm}$ from the cut end of the spinal cord. $B$, Average distribution of $\left[\mathrm{Ca}^{+2}\right]_{i}$ in axons $1 \mathrm{~d}$ after transection. All transections were performed in the animal. To calculate the average distributions, each set of data (from 4 separate experiments) was aligned so that the first point was located at the average distance of the tip of these axons from the cut end of the spinal cord. Each data point is the mean of all determinations that fell within $\pm 50 \mu \mathrm{m}$ of the distance indicated on the graph. Error bars indicate the SD of the mean. The solid circles represent the mean $\left[\mathrm{Ca}^{+2}\right]_{i}$ from uncut axons in 25 animals.

at low calcium levels, or they may result from a difference in the in vitro versus the in vivo fluorescence spectra for fura 2 (Williams et al., 1985; Konishi et al., 1988). Konishi et al. (1988) found that there was a difference in the $A$ of fura 2 in skeletalmuscle cells when compared to aqueous standards. They suggested that the main cause of this difference was that the fura 2 was bound to intracellular proteins, and that this binding caused a change in the spectra, which resulted in the in vivo calibration curve having both a lower $R_{\max }$ and a lower $R_{\min }$ than the in vitro curve. Although Williams et al. (1985) stated 
that there was no significant difference in the $\underline{A}$ of fura 2 in vitro versus in vivo, they did find a slight difference between the calibration curves in the 2 different environments. When we determined the in vivo and in vitro values for $A$, we found that it was higher in the axon than in calcium standards. Konishi et al. (1988) also found a higher $\underline{A}$ in vivo, though they found that $A$ in the skeletal-muscle cells was 0.272 , which is about twice our in vivo value. Such high values of $\underline{A}$ could not be obtained in vitro by simply increasing the viscosity of the solutions to intracellular levels; they could only be obtained by adding proteins to the standard solutions. This contrasts to our findings that an $A$ value similar to that in vivo could be obtained from standard solutions whose viscosity had been increased to $2 \mathrm{cP}$, a viscosity similar to that of cytoplasm (David-Dufilho et al., 1988). Both our values for $A$ and those of Konishi et al. (1988) are different from the 0.08 (in vivo) and 0.05 (in vitro) reported by Williams et al. (1985).

To support further our conclusion that fura 2 was not binding to proteins in the axons, we measured the diffusion coefficient of fura $2\left(D_{f}\right)$ in the axon. There are 2 reports that fura 2 diffuses more slowly in muscle cells than in free solution. Timmerman and Ashley (1986) have measured a $D_{f}$ of $3.9 \times 10^{-7} \mathrm{~cm}^{2} / \mathrm{sec}$ in barnacle muscle cells and $5.0 \times 10^{-6} \mathrm{~cm}^{2} / \mathrm{sec}$ in free solution. Baylor and Hollingworth (1988) measured a $D_{f}$ of $3.6 \times 10^{-7}$ $\mathrm{cm}^{2} / \mathrm{sec}$ in frog skeletal muscle and suggested that this value was lower than the value in free solution because of binding of the fura 2 to intracellular components. Our value for $D_{f}$ indicates that fura 2 is not significantly bound in the axon, and that the decrease in $D_{f}$ is due to the increased in vivo viscosity. Because our elevated intracellular $\underline{A}$ and our decreased $D_{f}$ could be accounted for solely by an increase of viscosity to levels known to exist in cytoplasm, we did not consider the effects that protein binding may have on our determinations of $\left[\mathrm{Ca}^{2+}\right]_{i}$. It is still possible that the true basal level is higher than we have determined; however, this should not affect the relative magnitude of the changes in concentration we have measured.

The 2 measuring systems report very similar values for the resting $\left[\mathrm{Ca}^{2+}\right]_{i}$ and the spatial distributions. The PMT system seems to have a better $\left[\mathrm{Ca}^{2+}\right]$ sensitivity than the video system; we found that it is possible to distinguish between 2 areas that differ by as little as $5 \mathrm{nM}$ using the PMT system. The PMT system also gives more repeatable values for the $\left[\mathrm{Ca}^{2+}\right]_{i}$. The video imaging system not only produces a better combination of both temporal and spatial distributions (the PMT system can do one or the other), but it also gives finer spatial resolution. We also found that the calibration of the video system is more complex than that for the PMT system.

The large, rapid increase in the distal $0.5 \mathrm{~mm}$ of the axon is probably caused by diffusion of calcium ions from the medium into the open end of the axon; however, the rapid elevation we observed at $1.6 \mathrm{~mm}$, and at distances more proximal to the cell body, occurred too rapidly to be caused by diffusion from the cut end, because the diffusion coefficient for calcium in axoplasm is about $1.2 \times 10^{-6} \mathrm{~cm}^{2} / \mathrm{sec}$ (Hodgkin and Keynes, 1957; Chang, 1986). One possible explanation for this rapid increase is that voltage-gated calcium channels are opened because of membrane depolarization over the distal $2-3 \mathrm{~mm}$ of the severed axons (Fig. 10). A propagated release of $\mathrm{Ca}^{2+}$ from intracellular stores (Palade, 1987) may be causing the second phase of calcium changes. Lipscombe et al. (1988) have shown in frog neurons that, after $\mathrm{Ca}^{2+}$ channels have closed, there is a continued increase in the $\left[\mathrm{Ca}^{2+}\right]_{i}$. Although they describe a transient in- crease and a rapid return to basal level in response to brief stimulation, we expect there to be continued stimulation following transection. Calcium-induced calcium release may vary with distance from the cut end because of the graded depolarization that occurs. The subsequent decline in the second phase may be due to an increased activity of plasma-membrane calcium pumps or increased intracellular sequestering (Nicholls, 1986). There may also be a permanent inactivation of the calcium channels by a $\mathrm{Ca}^{2}$-activated protein phosphatase (Armstrong, 1989). It is likely that the changes we observed are due to a combination of all of these mechanisms.

We assume that the third phase is due to the diffusion of calcium up the axon from the cut end, augmented by electrophoresis. Electrophoresis may contribute because the graded collapse of the membrane potential produces an electric field in a distal-proximal direction in the cut axon. We attempted to model the movement of calcium into the axon with a simple diffusion equation (Crank, 1975, Eq. 2.45):

$$
C=C_{o} \operatorname{erfc}(z)
$$

where $\operatorname{erfc}(z)=1-\operatorname{erf}(z)$ and $z=x /\left(2 D_{\mathrm{Ca}} t\right)$. We assumed that the axon was a semi-infinite space with an initially $0\left[\mathrm{Ca}^{2+}\right]_{i}$ and an unchanging calcium concentration of $2.6 \mathrm{mM}$ at the cut surface. The expected changes in calcium at each of the distances shown in Figure $3 \boldsymbol{A}$ were calculated. Although this approach produced curves (not shown) that had a similar form to the experimental data for the third phase, no single value for the apparent $\mathrm{Ca}^{2+}$ diffusion coefficient $\left(D_{\mathrm{Ca}}\right)$ produced curves that fit the data well at every distance. Values for $D_{\mathrm{Ca}}$ had to be varied between $5 \times 10^{-8}$ and $2 \times 10^{-7} \mathrm{~cm}^{2} / \mathrm{sec}$ to produce the best fits to the observed data. Donahue and Abercrombie (1987) have found that the diffusion of labeled calcium in Myxicola axoplasm could not be described by a single $D_{\mathrm{Ca}}$ when they carried out their experiments under physiological conditions. This is not surprising, because axons have powerful homeostatic mechanisms for regulating calcium levels. The assumption that the extracellular $\left[\mathrm{Ca}^{2+}\right]$ is unchanging might also be incorrect, as Young et al. (1982) measured a decreased extracellular $\left[\mathrm{Ca}^{2+}\right]$ for up to $3 \mathrm{hr}$ following a contusion injury to a mammalian spinal cord. Nevertheless, the general resemblance of the time course for this phase to that predicted by simple diffusion suggests that diffusion from the cut end is the dominant factor in these changes. The amount of calcium entering the cut end seems to overwhelm the cell's homeostatic mechanisms, at least temporarily.

The results of transecting the spinal cord in LCS clearly show that all of the changes previously described are dependent on extracellular $\mathrm{Ca}^{2+}$. This is not to say that the source for all 3 of the phases of increase is the external $\mathrm{Ca}^{2+}$, but rather, that the impetus for all 3 phases is the external $\mathrm{Ca}^{2+}$. The lack of an increase in $\left[\mathrm{Ca}^{2+}\right]_{i}$ when the spinal cord is transected in LCS may be related to the absence of an influx either as the source of the $\mathrm{Ca}^{2+}$ that causes the increase or as a trigger for release of $\mathrm{Ca}^{2+}$ from internal stores. It also may be that, after the spinal cord is soaked in LCS, the internal stores are depleted.

Two hr after transection in the normal $\mathrm{Ca}^{2+}$-containing medium, the $\left[\mathrm{Ca}^{2+}\right]_{i}$ in the terminal $1.0 \mathrm{~mm}$ of the cut axon is high enough to activate at least 1 form of a calcium-activated neutral proteinase known to exist in axons (Kawashima et al., 1986; Nixon, 1986). We are uncertain whether the concentration is also high enough to cause dissociation of microtubules because there is some conflict concerning the value of $\left[\mathrm{Ca}^{2+}\right]_{i}$ that will 


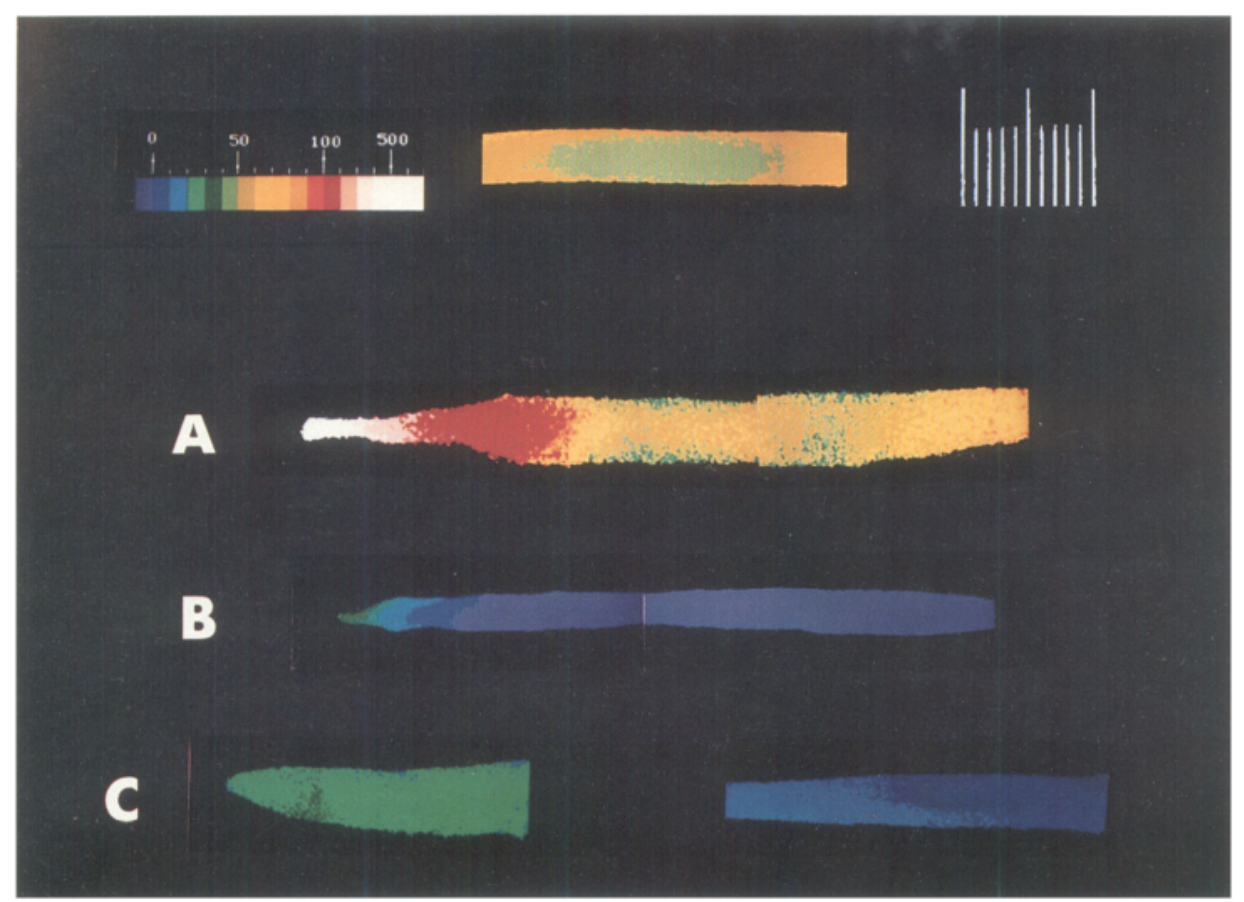

Figure 12. Visualization of distribution of $\left[\mathrm{Ca}^{+2}\right]_{i}$ in axons $1 \mathrm{~d}$ after transection. $A, B$, and $C$ are the results of representative experiments, where the transection was performed in the animal, which was then allowed to recover for $1 \mathrm{~d}$. The cut end of the spinal cord is located out of the field to the left of these images. The color scale is different than that in Figure 4 to show more detail in the lower calcium-concentration range. The gap between images in $C$ is about $150 \mu \mathrm{m}$. The violet seen in most of $11 \mathrm{~B}$ represents ratios below the calibrated ratio for $0\left[\mathrm{Ca}^{2+}\right]$. A representative image from an uncut axon is shown between the color scale and the distance scale (see note in Fig. $4 A$ concerning variation in this segment). The distance scale is an image of an objective micrometer slide at the same magnification as the color images; each division is $10 \mu \mathrm{m}$. The color scale in the upper left shows the correspondence between $\left[\mathrm{Ca}^{2+}\right]_{i}$ in nM and the colors used in the images.

cause this (Kiehart, 1981; Keith et al., 1983). Correlation of the dieback of these axons with any of these mechanisms will require further experiments. For example, measurements of the distribution of cytoskeletal elements before and after transection and at $1 \mathrm{~d}$ posttransection in these animals would be important. Also, because of our uncertainty about the calibration of the fura 2 fluorescence ratios and the fact that the $\left[\mathrm{Ca}^{2+}\right]_{i}$ goes above $10 \mu \mathrm{M}$ (the saturating level for fura 2), some additional measurements of the $\left[\mathrm{Ca}^{2+}\right]_{i}$ with different techniques may be necessary.

We were surprised to find that the ends of the axons (as determined by the abrupt end of the fluorescence) were only $0.25 \mathrm{~mm}$ from the cut end of the spinal cord $1 \mathrm{~d}$ after transection. We had expected, given the high $\left[\mathrm{Ca}^{2+}\right]_{i}$ we observed in the distal $2 \mathrm{~mm}$ following transection, that this portion of the axon would have already degenerated. Schlaepfer and Bunge (1973) found that single nerve fibers isolated in a culture dish degenerated between 6 and $24 \mathrm{hr}$ after transection in their normal calciumcontaining medium. One reason for the lack of degeneration we observed at $1 \mathrm{~d}$ posttransection may be that the axon was surrounded by support tissues rather than isolated in a culture dish.

It is unclear whether the cut end of the axon had degenerated after $1 \mathrm{~d}$ or whether it had simply retracted. Gross et al. (1983) found that the neurites of isolated cultured nerve cells would retract within $1 \mathrm{~d}$ of transection, but this situation is quite different from the Mauthner axons, which are embedded in a spinal cord with connective tissues around them. In a more similar preparation, the cockroach nerve cord, Meiri et al. (1983) stated, "Intracellular staining of the proximal segment of the transected giant axons ... reveals that 24 hours after axonal transection, the cut end retracts." They did not give the distance that these axons retract, nor did they distinguish between retraction and degeneration.

The very low, sometimes negative, values for the $\left[\mathrm{Ca}^{2+}\right]_{i}$ we observed in axons that had been transected $1 \mathrm{~d}$ previously may have been caused by a change in the intracellular environment. For example, we have some preliminary data that suggest that the $\underline{A}$ of fura 2 in these recovering axon tips is different from that in the uncut axons. The low values could also be due to an overcompensation by the calcium homeostatic mechanisms. The variability illustrated in Figure 9 may result from axons in various stages of resealing. We do not know if this variability reflects a changing pattern of $\left[\mathrm{Ca}^{2+}\right]_{i}$ in the axon's tip as it heals or whether it is a variability between animals. We did not observe any correlation between the distribution of $\left[\mathrm{Ca}^{2+}\right]_{i}$ in the tip and the distance of the end of the axon from the cut end of the spinal cord.

The presence of a limiting membrane at the end of the axon $1 \mathrm{~d}$ after transection (Clark and Wickelgren, 1982) does not necessarily indicate that the axon is normal by this time. It is important to note, however, that the $\left[\mathrm{Ca}^{2+}\right]_{i}$ returned to near normal. This means that microtubules may have repolymerized, and that calcium-activated proteinases may no longer be active. Considering the levels of $\left[\mathrm{Ca}^{2+}\right]_{i}$ that were observed in the end of the axon, however, the intracellular environment has likely been changed from the precut condition. It is interesting that the $\left[\mathrm{Ca}^{2+}\right]_{i}$ rises to micromolar levels for about $2 \mathrm{~mm}$ back from the cut end, because this is about the distance to which these axons eventually degenerate (Roederer et al., 1983). Although the elevated calcium does not immediately destroy the axon, it may be that events are set in motion that later lead to axonal degeneration in this region, and the area of elevated calcium concentration may determine how far from the cut end the axons degenerate.

Roederer et al. (1983) also determined the effects of applied electrical fields on dieback of transected lamprey giant axons. They passed $10 \mu \mathrm{A}$ of DC current across the site of transection and found that the dieback distance of the proximal segment was reduced, compared to controls, from 1.75 to $0.74 \mathrm{~mm}$ if the direction of the current was rostral-caudal, and the dieback distance was increased to $2.82 \mathrm{~mm}$ if the current direction was caudal-rostral. Current was passed by implanting wick electrodes in the body musculature of the intact animal, and dieback was assessed $5 \mathrm{~d}$ after transection. They suggested that these effects on dieback were mediated by the reduction or increase 
of calcium entry into the severed axons. The applied currents would be expected to enter the axons because of their cable properties, and the electrical field in the axoplasm should equal that of the surrounding extracellular space, especially near the cut end. We found that applied fields do modulate the movement of $\mathrm{Ca}^{2+}$ into the axons through the cut end in the expected way. The third phase of the increase in $\left[\mathrm{Ca}^{2+}\right]_{i}$, which we associate with diffusion and electrophoresis into the axon from the cut end, is nearly abolished by a field of $10 \mathrm{mV} / \mathrm{mm}$ applied in the rostral-caudal direction and is enhanced by a caudalrostral field. We were surprised that these relatively small fields had such large effects. In the absence of an applied field, the influx of $\mathrm{Ca}^{2+}$ due to the concentration gradient and the influx due to the endogenous field (Fig. 10) are similar if reasonable assumptions about the concentration gradient are made (calculations not shown). Therefore, if the applied field exactly canceled the endogenous fields, the influx of $\mathrm{Ca}^{2+}$ through the cut end would only be halved, approximately. The fact that the third phase of the increase in $\left[\mathrm{Ca}^{2+}\right]_{i}$ did not occur suggests that the amount of $\mathrm{Ca}^{2+}$ that enters the axon in the third phase exceeds by only a factor of 2 or so what the cell's homeostatic mechanisms can handle. An additional consideration is suggested by our finding that fura 2 is better retained in severed axons in the presence of an applied rostral-caudal field. It would be expected that other small, negatively charged molecules, such as ATP, would also be retained; even the retention of organelles such as mitochondria might be increased. This would help the cell deal with the calcium load that results from transection.

Our observation that applied electrical fields can influence the distribution of charged molecules is not unprecedented. Baker and Crawford (1972) showed that the location of a bolus of radioactive magnesium in squid axons shifted toward the cathode in an applied field. They also found that a similar bolus of radioactive calcium was not moved by the ficld, confirming the earlier work of Hodgkin and Keynes (1957). Of course, these investigators were looking at total calcium, most of which was sequestered in some way, while we studied only free calcium. More recently, Cooper et al. (1989) showed that carboxyfluorescein could be electrophoretically redistributed by applied fields in coupled giant neurons of crayfish. Thus, it is clear that small, externally applied electrical fields can penetrate axons and affect the distribution of charged entities, including physiologically important ones such as $\mathrm{Ca}^{2+}$. This may explain some of the effects of applied fields on neuronal growth, degeneration, and regeneration.

\section{References}

Armstrong DL (1989) Calcium channel regulation by calcineurin, a $\mathrm{Ca}^{2+}$-activated phosphatase in mammalian brain. TINS 12:117-122. Baker PF, Crawford AC (1972) Mobility and transport of magnesium in squid giant axons. J Physiol (Lond) 227:855-874.

Baylor SM, Hollingworth S (1988) Fura-2 calcium transients in frog skeletal muscle fibres. J Physiol (Lond) 403:151-192.

Borgens RB, Jaffe LF, Cohen MJ (1980) Large and persistent electrical currents enter the transected lamprey spinal cord. Proc Natl Acad Sci USA 77:1209-1213.

Cantor CR, Schimmel PR (1980) Biophysical chemistry. New York: W. Freeman.

Chang D (1986) Axonal transport and the movement of ${ }^{45} \mathrm{Ca}$ inside the giant axon of squid. Brain Res 267:319-322.

Clark, RD, Wickelgren WO (1982) Effects of spinal transection on brain cell bodies and proximal and distal spinal axonal segments of the lamprey. Soc Neurosci Abstr 8:914.

Cohen AH, Mackler SA, Selzer ME (1986) Functional regencration following spinal transection demonstrated in the isolated spinal cord of the larval sea lamprey. Proc Natl Acad Sci USA 83:2763-2766.

Cooper MS, Miller JP, Faser S (1989) Electrophoretic repatterning of charged cytoplasmic molecules within tissues coupled by gap junctions by externally applied electrical fields. Dev Biol 132:179-188.

Cork J, Reinach P, Moses J, Robinson KR (1987) Calcium does not act as a second messenger for adrenergic and cholinergic agonists in corneal epithelial cells. Curr Eye Res 6:1309-1317.

Crank J (1975) The mathematics of diffusion, Oxford: Clarendon.

David-Dufilho M, Montenay-Garestier T, Devynck M-A (1988) Fluorescence measurements of free $\mathrm{Ca}^{2+}$ concentration in human erthrocytes using the $\mathrm{Ca}^{2+}$-indicator fura-2. Cell Calcium 9:167-179.

DiPolo R, Requena J, Brinley FJ Jr, Mullins LJ, Scarpa A, Tiffert T (1976) Ionized calcium concentrations in squid axons. J Gen Physiol 67:433-467.

DiPolo R, Rojas H, Vergara J, Lopez R, Caputo C (1983) Measurements of intracellular ionized calcium in squid giant axons using calcium-sensitive electrodes. Biochim Biophys Acta 728:311-318.

Donahuc BS, Abcrcrombic RF (1987) Frec diffusion coefficient of ionic calcium in cytoplasm. Cell Calcium 8:437-448.

Gross GW, Lucas JH, Higgins ML (1983) Laser microbeam surgery: ultrastructural changes associated with neurite transection in culture. J Neurosci 3:1979-1993.

Grynkiewicz G, Poenie M, Tsien RY (1985) A new generation of $\mathrm{Ca}^{2+}$ indicators with greatly improved fluorescence properties. J Biol Chem 260:3440-3450.

Happel RD, Smith KP, Banik NL, Powers JM, Hogan EL, Balentine JD (1981) $\mathrm{Ca}^{++}$accumulation in experimental spinal cord trauma. Brain Res 214:476-479.

Hodgkin AL, Keynes RD (1957) Movements of labelled calcium in squid giant axons. J Physiol (Lond) 138:253-281

Kao CC, Wrathall JR, Kyoshima K (1983) Axonal reaction to transcction. In: Spinal cord reconstruction (Kao CC, Bunge RP, Reier PJ, eds), pp 41-57. New York: Raven.

Kawashima S, Inomata M, Imahori K (1986) Autolytic and proteolytic processes of calcium-activated neutral protease are independent from each other. Biomed Res 7:327-331.

Keith C, DiPaola M, Maxfield FR, Shelanski ML (1983) Microinjection of $\mathrm{Ca}^{++}$-calmodulin causes a local depolymerization of microtubules. J Cell Biol 97:1918-1924.

Kiehart DP (1981) Studies on the in vivo sensitivity of spindle microtubules to calcium ions and evidence for a vesicular calcium-sequestering system. J Cell Biol 88:604-617.

Konishi M, Olson A, Hollingworth S, Baylor SM (1988) Myoplasmic binding of fura- 2 investigated by steady-state fluorescence and absorbance measurements. Biophys J 54:1089-1104.

Koppel DE, Axelrod D, Schlessinger J, Elson EL, Webb WW (1976) Dynamics of fluorescence marker concentration as a probe of mobility. Biophys J 16:1315-1329.

Lipscombe D, Madison DV, Poenie M, Reuter H, Tsien RW, Tsien RY (1988) Imaging of cytosolic $\mathrm{Ca}^{2+}$ transients arising from $\mathrm{Ca}^{2+}$ stores and $\mathrm{Ca}^{2+}$ channels in sympathetic neurons. Neuron 1:355-365.

Lucas JH, Gross GW, Emery DG, Gardner CR (1985) Neuronal survival or death after dendrite transection close to the perikaryon: correlation with electrophysiologic, morphologic, and ultrastructural changes. Cent Nerv Syst Trauma 2:231-255.

Meiri H, Dormann A, Spira ME (1983) Comparison of ultrastructural changes in proximal and distal segments of transected giant fibers of the cockroach Periplaneta americana. Brain Res 263:1-14.

Nicholls DG (1986) Intracellular calcium homeostasis. Br Med Bull 42:353-358.

Nixon RA (1986) Fodrin degradation by calcium-activated neutral proteinase (CANP) in retinal ganglion cell neurons and optic glia: preferential localization of CANP activity in neurons. J Neurosci 6: 1264-1271.

Palade $\mathrm{P}$ (1987) Drug-induced $\mathrm{Ca}^{2+}$ release from isolated sarcoplasmic reticulum. I. Use of pyrophosphate to study caffeine-induced $\mathrm{Ca}^{2+}$ release. J Biol Chem 262:6135-6141.

Pumain R (1988) Calcium Ions. In: Neuromethods \#9: neuronal microenvironment (Boulton AA, Baker GB, Walz W, eds), pp 589-650. Clifton, NJ: Humana.

Robinson KR (1989) Endogenous and applied electrical currents: their measurement and application. In: Electrical fields in vertebrate repair (Borgens RB, Robinson KR, Vanable JW Jr, McGinnis ME, eds), pp 1-25. New York: Liss. 
Roederer E, Goldberg NH, Cohen MJ (1983) Modification of retrograde degeneration in transected spinal axons of the lamprey by applied DC current. J Neurosci 3:153-160.

Schlaepfer WW (1974) Calcium-induced degeneration of axoplasm in isolated segments of rat peripheral nerve. Brain Res 69:203-215.

Schlaepfer WW (1977) Structural alterations of peripheral nerve induced by the calcium ionophore A23187. Brain Res 136:1-9.

Schlaepfer WW, Bunge RP (1973) Effects of calcium ion concentration on the degeneration of amputated axons in tissue culture. J Cell Biol $59: 456-470$.

Timmerman MP, Ashley CC (1986) Fura-2 diffusion and its use as an indicator of transient free calcium changes in single striated muscle cells. FEBS Lett 209:1-8.
Wickelgren WO, Leonard JP, Grimes MJ, Clark RD (1985) Ultrastructural correlates of transmitter release in presynaptic area of lamprey reticulospinal axons. J Neurosci 5:1188-1201.

Williams DA, Fogarty KE, Tsien RY, Fay FS (1985) Calcium gradients in single smooth muscle cells revealed by the digital imaging microscope using fura-2. Nature 318:558-561.

Yin H-S, Selzer ME (1983) Axonal regeneration in lamprey spinal cord. J Neurosci 3:1135-1144.

Young W, Yen V, Blight A (1982) Extracellular calcium ionic activity in experimental spinal cord contusion. Brain Res 253:105-113.

Zelena J, Lubinska L, Gutmann E (1968) Accumulation of organelles at the ends of interrupted axons. Z Zellforsch 91:200-219. 